\title{
AS VINTE E UMA FACES DE EXU NA FILOSOFIA AFRODESCENDENTE DA EDUCAÇÃO (RESENHA)
}

\begin{abstract}
SOARES, Emanoel Luís Roque. As vinte e uma faces de Exu na filosofia afrodescendente da educação. Cruz das Almas/Belo Horizonte: EdUFRB/Fino Traço, 2016.
\end{abstract}

\section{Aline Matos da Rocha"}

De acordo com Bidima (2017, p. 01),

Não podemos entrar na filosofia, assim como na vida, senão misturados a uma história que nos precede e enredados em histórias que se tecem entorno $e$ sobre nós. Histórias nas quais se sondam nossas próprias constituições e situaçôes, histórias nas quais se separam narrativas intricadas que nos levam e transportam em direção a um outro lugar; [...]. Temos, então, a necessidade, enquanto seres históricos, de nos contar histórias.

Sob a necessidade de nos contar histórias e confrontar as que nos são contadas, Emanoel Luís Roque Soares escreve As vinte e uma faces de Exu na filosofia afrodescendente da educação. É importante frisar que aquela foi a sua tese de doutorado apresentada ao Programa de PósGraduação em Educação da Universidade Federal do Ceará - UFC. Sendo um dos títulos que compõem a Coleção UNIAFRO

\footnotetext{
* Mestranda em Filosofia no PPGFIL/FAFIL - UFG. Licenciada e Bacharela em Filosofia pela UnB. Email: matosdarochaaline@gmail.com
}

(NEAB-UFRB), que privilegia a publicação de coletâneas que ofereçam subsídios materiais-pedagógicos para as professoras $e$ professores, pesquisadoras e pesquisadores em múltiplas abordagens interdisciplinares, "objetivando a implantação e difusão de produtos vinculados à Lei $\mathrm{n}^{\circ} 11.645$ de 2008" (SOARES, 2016, p. 13), que determina a obrigatoriedade do ensino da História da África, da Cultura Afro-Brasileira e dos Povos Indígenas nos currículos da Educação Básica.

Ao forjar (ao modo de Ogum) uma filosofia afrodescendente da educação sob as faces (bases) de Exu, Soares contempla a prescrição da Lei no 11.645/2008, e amplia os caminhos educacionais, pois nos convida a educar às avessas - como fez Exu ao ensinar Oxum o jogo de búzios. Desse modo, traça as possibilidades de uma educação filosófica por meio de Exu, ressaltando a importância do orixá como um propulsor para o nosso conhecimento da filosofia africana e afrodiaspórica, am- 
bas, pouco conhecidas e estudadas nas academias brasileiras. Estas que além de ser um espaço de pesquisa, são as principais formadoras de professoras e professores, que precisam dialogar com outras vozes para poder ensiná-las e fomentá-las em suas/seus estudantes. Reconhecendo também as vozes e experiências daquelas $e$ daqueles. De acordo com Hooks (2013, p. 119), cada estudante "tem suas lembranças, sua família, sua religião, seus sentimentos, sua língua e sua cultura que the dão uma voz característica", a qual deve ser levada em consideração no processo educativo. Em virtude disso, o livro salienta o aspecto interdisciplinar de Exu e os diálogos que o pensamento mobilizado pelo orixá estabelece com outras vozes, fomentando diversos enfrentamentos, tais como religiosos, educacionais e epistemológicos, buscando modificar "os modos estabelecidos do saber" (HOOKS, 2013, p. 187).

Em face(s) do exposto, o livro é composto por quatro capítulos - e não dividido, já que "a vida não se fatia" (HAMPATÉ BÂ, 2010, p. 175). De modo que, no capítulo denominado Método, Soares expõe a escolha do caminho que será percorrido com Exu. Nesse sentido, o método adotado será o fenomenológico e o genealógico. O autor antecipando a pergunta: "será que um método ocidental serve para uma pesquisa de matriz africana?" (SOARES, 2016, p. 31), apresenta sua compreensão da fenomenologia e explica porque considera a sua utilização um caminho profícuo para estudar Exu. Para Soares (2016, p. 32):

A fenomenologia é uma espécie de comunicação da realidade à nossa consciência, uma maneira de conversar com o problema de pesquisa, de inquiri-lo, de dialogar com ele para compreendê-lo, interpretá-lo; faz-se necessário um interrogar constante de rigor filosófico para que o fenômeno venha a se mostrar. Dessa forma, tal como o nosso objeto, no caso Exu, para o olhar fenomenológico, não pode existir uma só realidade, pois existem várias interpretações $e$, assim sendo, da mesma maneira que existem vários Exus e todos reais, as verdades fenomenológicas também são várias, todas reais e relativas, a quem as percebe $e$ as interpreta de acordo com a sua perspectiva. É um compromisso um engajamento, sendo que não existe neutralidade e, sim, uma cumplicidade, uma escolha, quer dizer, a intencionalidade de um perceber perspectivo relativo, porém rigoroso.

Exu - imerso entre ser e não ser - é fenomenológico, pois nos comunica realidades análogas a um diamante que precisa ser observado e reconhecido em seus diversos lados e dimensões. Já o método 
genealógico é utilizado no sentido nietzschiano, introduzindo a compreensão de Foucault, para o qual aquela investiga as ligações entre as formações de saber $e$ as relações de poder. Em Soares (2016, p. 34):

A genealogia é necessária para que eu aprenda num retornar a Exu, não para traçar uma curva evolutiva, mas para compreender e reconhecer as diferentes cenas e papéis distintos de cada ator histórico. Nesta trilha genealógica, as palavras do Nietzsche para com a história da moral servem para o meu pensar em relação a Exu, pois tanto a moral quanto o modo de ser de Exu foram deturpados, alterados por aqueles que, na forma luxuriosa de se manter hegemônicos manusearam os conceitos legislando em causa própria, uma vez que a história da moral, assim como a história de Exu, sempre ou quase sempre é contada e formatada estrategicamente por quem vence, quer vencer, ou por quem detém ou a qualquer custo quer deter $\mathrm{o}$ poder.

Não podemos esquecer as palavras de Bidima (2017, p. 01), que nos alerta sobre a necessidade de nos contar histórias e também da necessidade de fazer "como se nossas narrativas sobre o belo, o verdadeiro, o bem não fossem as mesmas histórias que os humanos se contam em todos os lugares". Dessa forma, compete ao ge- nealogista olhar para a história e se questionar: no que Exu se transformou ao chegar no Brasil? Que discursos são produzidos em relação à Exu?

$\mathrm{Na}$ trilha do orixá, o capítulo intitulado Motivaçóes, traduz as experiências de Soares com a cultura africana, e como esta ecoa no seu pensar africanamente e educar filosófico afrodescendente. O livro acentua por meio do seu autor, que não há uma cisão entre vida e escrita. Em virtude disso, Soares mobiliza um posicionamento boçal, este questiona (confronta) a ordem. O boçal é contrário a europeização do Brasil e seu perverso apagamento das contribuições indígenas e africanas. Segundo Soares (2016, p. 54):

Sou boçal, por mais pejorativo que seja o sentido desta palavra hoje, não sou ladino e nem crioulo, luto com resistência para não ver o desaparecimento de uma cultura que, embora seja um atraso pelos ditos civilizados europeus, é para mim uma maneira de ser e viver africanamente, que tem muito a ensinar aos doutores ocidentais $e$ às suas categorias que até hoje não deram conta dos problemas sociais do mundo.

A saber, as categorias europeias possuem seus limites e não podem, de modo absoluto, dar conta dos problemas sociais brasileiros. O não reconhecimento dessa afirmação tanto atesta a nossa negação das 
bases culturais afro $e$ indígena, quanto o nosso racismo que se manifesta de diversas faces: institucional, epistemológica, etc. Desse modo, é muito importante e significativa a estrada sob a qual o livro vem caminhando, a qual coloca as categorias ocidentais para dialogar com as afrodescendentes.

No capítulo seguinte, designado Conceitos, discorre sobre o papel fundamental do mito na filosofia afrodescendente da educação. Tendo em vista que uma das formas dos povos se educarem e compreenderem as clássicas inquietações: de onde viemos, o que somos e para onde vamos? É por meio das narrativas míticas, que estão presente em todo o livro, contando $e$ (en)cantando as traquinagens de Exu, que por ser o princípio da comunicação entre o Òrun $^{2}$ e o Àiyé ${ }^{3}$ está constantemente produzindo conceitos: éticos, políticos, estéticos, lógicos e epistemológicos. O orixá também é o responsável por traduzir e refletir - como o abebê $\hat{e}^{4}$ de Oxum - a experiência existencial, afetiva e religiosa de Soares em Cachoeira, no Recôncavo da Bahia. Para Soares (2016, p. 87):

É neste lugar, onde eu me reconheço no outro, que as coisas,

\footnotetext{
2 Céu.

3 Terra.

${ }^{4}$ Espelho.
}

os acontecimentos, as pessoas falam de mim para mim mesmo, contam-me como eu sou, relembram de onde vim, do que eu gosto, como eu falo, como vejo o mundo, em que eu acredito e que, por isso, torna em mim forte a identidade, o pertencimento, a lembrança da cultura africana, a qual juntamente com a indígena e portuguesa, fazem parte do meu eu, afrodescendente que sou.

O livro ao invocar constantemente o ponto de vista dos afrodescendentes, inverte as narrativas que não levam em conta aqueles como sujeito e enunciadores da sua própria fala. Em vista disso, o autor ressalta que a vida individual e coletiva dos afrodescendentes brasileiros está plena de Exu. Este para o povo de santo é a energia que movimenta tudo. Nesse sentido, as religiões de matrizes africanas são as próprias expressões do orixá.

No tópico, olhares femininos sobre $E x u$, há tanto o olhar (da porteira pra fora) da antropóloga estadunidense Ruth Landes, que chega na década de 30 em Salvador - BA, para realizar seus estudos doutorais, nos quais resultam na obra $A$ cidade das mulheres, que disserta sobre a matrifocalidade para além das famílias de santo. Quanto as falas da Ialorixá Juciara Silva da Paixão, "Preta de Oxaguiã, filha e herdeira do Axé de Gaudina Silva, conhecida como 
Mãe Baratinha” (SOARES, 2016, p. 107). A "Dagã do Ilê Kayô Alaketú Ashé Óxum, Cátia Virgínia de Melo Souza" (SOARES, 2016, p. 108). O de Maria Stela de Azevedo Santos "Odé Kaiodê, Kolabá (Mãe Stela de Oxossi) (SOARES, 2016, p. 118). E sem ser a fala que finaliza, mas a que reúne todas as outras, a de Gaiacu Luisa, a qual o livro presta memória. Tendo em vista que a sua entrevista foi concedida no dia 31 de março, três meses antes do seu falecimento com 95 anos.

Cabe ressaltar que todas essas falas estão em consonância com a força que anima a de Maa Ngala para Hampaté Bá (2010), Olodumaré ou Olorum para as mulheres de axé. Dado que nas religiões de matrizes africanas os deuses possuem muitos nomes, faces e modos de nos educar a viver, e não simplesmente passar pela vida.
Como o sentido se constrói feito trilhas sobre o mato, na Conclusão - que pode ser o início, pois para Exu, o fim pode ser o início e vice-versa - Soares chama nossa atenção para que não percamos o caminho que ele veio traçando na companhia de Exu, que carrega consigo as múltiplas possibilidades para uma filosofia afrodescendente da educação comprometida com "uma visão de mundo contrahegemônica" (HOOKS, 2013, p. 228). Ou seja, uma educação que tenha profunda ligação com a transgressão e a prática da liberdade. Princípios que o livro promove constantemente por meio de uma empreitada exuriana que busca um educar filosófico mais plural, vinculado as realidades étnico-sociais brasileiras.

\section{Referências}

BIDIMA, Jean-Godefroy. Da Travessia: contar experiências, partilhar o sentido. Tradução para uso didático por Gabriel Silveira de Andrade Antunes. Disponível em: < http://filosofiaafricana.weebly.com >. Acesso em: 28 de abr. de 2017.

HAMPATÉ BÂ, Amadou. A tradição viva. In: KI-ZERBO, Joseph (ed.). História Geral da África I. Metodologia e Pré-história da África. Brasília: Unesco, 2010.

HOOKS, bell. Ensinando a transgredir: a educação como prática da liberdade. Tradução de Marcelo Brandão Cipolla. São Paulo: Editora WMF Martins Fontes, 2013.

SOARES, Emanoel Luís Roque. As vinte e uma faces de Exu na filosofia afrodescendente da educação. Cruz das Almas/Belo Horizonte: EdUFRB/Fino Traço, 2016. 